\title{
Optimal dose of aprotinin for neuroprotection and renal function in a piglet survival model
}

Yusuke Iwata, MD, Toru Okamura, MD, Nobuyuki Ishibashi, MD, David Zurakowski, PhD, Hart G. W. Lidov, MD, and

Richard A. Jonas, MD

Objective: The efficacy of aprotinin in reducing blood loss after cardiopulmonary bypass is well established, although its neuroprotective potential is less well known. Furthermore, there is controversy regarding optimal dosing and possible renal complications.

Methods: Fifty-four piglets were randomized to one of 3 cardiopulmonary bypass groups designed to carry the risk of postoperative cerebral and renal dysfunction: circulatory arrest at $25^{\circ} \mathrm{C}$ and ultra-low flow bypass $(10 \mathrm{~mL}$. $\mathrm{kg}^{-1} \cdot \min ^{-1}$ ) at either $25^{\circ} \mathrm{C}$ or $34^{\circ} \mathrm{C}$. Animals were randomized to the following groups: control (no aprotinin), low dose $(30,000 \mathrm{KIU} / \mathrm{kg}$ into prime only), standard full dose $(30,000 \mathrm{KIU} / \mathrm{kg}$ bolus administered intravenously into prime plus 10,000 KIU/kg infusion), and double full dose. The tissue oxygenation index was monitored by means of near-infrared spectroscopy. Neurologic functional and histologic scores and creatinine and blood urea nitrogen values were outcomes of interest.

Results: Aprotinin significantly improved neurologic scores on postoperative day 1 after ultra-low-flow bypass at $25^{\circ} \mathrm{C}$ or $34^{\circ} \mathrm{C}(P<.01)$ but not after hypothermic circulatory arrest $(P=.57)$. Linear regression indicated a strong dose-response relationship, with higher aprotinin doses having the best neurologic scores. During low-flow bypass, a higher tissue oxygenation index was correlated with a higher aprotinin dose $(P<.05)$. Aprotinin dose had no significant effect on creatinine or blood urea nitrogen values on day 1 . Low body weight was the only predictor of high blood urea nitrogen values $(r=-0.39, P<.01)$.

Conclusion: Aprotinin significantly improves neurologic recovery without compromising renal function in the young piglet.

Aprotinin is a broad-spectrum serine protease inhibitor isolated from bovine lung. It has anti-inflammatory effects and reduces postoperative blood loss after cardiopulmonary bypass (CPB) by blocking complement activation and reduction of fibrinolysis through inhibition of trypsin, plasmin, and kallikrein. ${ }^{1,2}$ However, the optimal dose of aprotinin has been controversial. Levy and colleagues ${ }^{2}$ reported that both low and high doses reduced postoperative blood loss. Kawasuji and associates ${ }^{3}$ reported that low-dose aprotinin could reduce postoperative blood loss. In general, the dose used for adults in contrast to pediatric dosing has not varied according to body surface area, and the blood level has not been monitored. Nuttall and coworkers ${ }^{4}$ reported that the dose of aprotinin adjusted by body weight was helpful to obtain the optimal plasma concentration of aprotinin and to avoid overdosing.

\footnotetext{
From the Division of Cardiac Surgery, Children's National Medical Center, Washington, DC.

Presented at the 88th Annual Meeting of the American Association for Thoracic Surgeons, May 11-14, 2008, San Diego, California.

Supported by National Institutes of Health grant R01HL060922.

Received for publication May 4, 2008; accepted for publication June 10, 2008.

Address for reprints: Richard A. Jonas, MD, Children's National Heart Institute, Chil-

dren's National Medical Center, 111 Michigan Ave NW, Washington, DC 20010

(E-mail: rjonas@cnmc.org).

J Thorac Cardiovasc Surg 2009;137:1521-9

$0022-5223 / \$ 36.00$

Copyright (C) 2009 by The American Association for Thoracic Surgery

doi:10.1016/j.jtcvs.2008.06.049
}

For many years, there have been intermittent reports of possible adverse effects of aprotinin, such as myocardial infarction or renal dysfunction. ${ }^{5-7}$ In 2006, Mangano and coworkers $^{8}$ reported, in an influential article in the New England Journal of Medicine, that aprotinin increased the risk of renal failure requiring dialysis, myocardial infarction, and stroke. Preliminary results of a prospective study in adults suggesting a possibly higher mortality because of bleeding led the US Food and Drug Administration to recommend that aprotinin not be marketed for any application, including pediatric $\mathrm{CPB}$.

In pediatric cardiac surgery major neurologic injury, such as choreoathetosis and loss of developmental potential, remain feared complications. The role of genetic factors, prenatal cerebral blood flow, and socioeconomic factors, as well as postoperative intensive care unit management, have been reported as influencing developmental outcome; nevertheless, 2 carefully designed prospective studies have implicated intraoperative factors as important determinants of developmental outcome after pediatric cardiac surgery. Aprotinin, however, has never been implicated as a cause of neurologic injury in children, despite its widespread use in pediatric cardiac surgery. In fact, several investigators have demonstrated the potential of aprotinin for neuroprotection. Kamiya and colleagues $^{9}$ reported that aprotinin improved preservation of cerebral adenosine triphosphate and reduced cerebral water content after ischemia. Aoki and associates ${ }^{10}$ used a piglet model and magnetic resonance spectroscopy to show that 


$$
\begin{aligned}
& \text { Abbreviations and Acronyms } \\
& \text { ANOVA }=\text { analysis of variance } \\
& \text { BUN = blood urea nitrogen } \\
& \mathrm{CPB}=\text { cardiopulmonary bypass } \\
& \text { DHCA = deep hypothermic circulatory arrest } \\
& \text { HCA = hypothermic circulatory arrest } \\
& \text { HS = histologic score } \\
& \text { NDS = neurologic deficit score } \\
& \text { NIRS = near-infrared spectroscopy } \\
& \text { TOI = tissue oxygenation index } \\
& \mathrm{ULF}=\text { ultra low flow }
\end{aligned}
$$

aprotinin improved acute recovery of cerebral energy metabolism after deep hypothermic circulatory arrest (DHCA), possibly through preservation of endothelial function in the cerebral microvasculature. Anttila and coworkers ${ }^{11}$ used cerebral intravital microscopy to demonstrate that aprotinin reduced inflammation and improved neurologic functional outcome after DHCA using a piglet survival model and the full pediatric Hammersmith dose regimen, although it did not improve histologic score (HS).

Reports in the neuroscience literature have suggested that serine protease inhibitors protect neurons from ischemic injury. ${ }^{12-14}$ Nicole and associates ${ }^{15}$ described reduced excitotoxic neuronal injury with exposure to the serpin plasminogen activator inhibitor-1, and Lebeurrier and colleagues ${ }^{16}$ reported that neuroserpin also protects neurons from glutamatergic excitotoxic neuronal cell death. Using a similar neuronal cell culture model, we reported that aprotinin also has a direct and dose-dependent neuroprotective effect against neuronal cell death caused by N-methyl-D-aspartate. ${ }^{17}$

The purpose of this piglet survival study was to investigate the optimal dose of aprotinin for neuroprotection and the effect of aprotinin on renal function.

\section{MATERIALS AND METHODS \\ Animals}

Fifty-four young ( $27 \pm 5$ days) Yorkshire piglets weighting $10.4 \pm 1.4$ $\mathrm{kg}$ were studied. All animals received humane care in accordance with the "Principles of laboratory animal care"' formulated by the National Society for Medical Research and the "Guide for the care and use of laboratory animals" prepared by the Institute of Laboratory Animal Resources, National Research Council, and published by the National Academy Press, revised in 1996. This study was approved by the Institutional Animal Care and Use Committee of the Children's National Medical Center.

\section{Surgical Preparation}

After premedication with an intramuscular injection of ketamine $(20 \mathrm{mg} /$ $\mathrm{kg}$ ) and xylazine ( $4 \mathrm{mg} / \mathrm{kg}$ ), the piglets were intubated with 5-mm cuffed endotracheal tubes and ventilated with $21 \%$ oxygen at a respiratory rate of between 12 and 16 breaths/min to achieve an arterial $\mathrm{PCO}_{2}$ of $40 \mathrm{~mm} \mathrm{Hg}$ with a pressure cycle ventilator (Sechrist IV-100B Ventilator; Sechrist Industries, Inc, Anaheim, Calif). After induction with an intravenous bolus, injection of fentanyl $(50 \mu \mathrm{g} / \mathrm{kg})$ and pancuronium $(0.5 \mathrm{mg} / \mathrm{kg})$, anesthesia was main- tained with continuous infusion of fentanyl $\left(25 \mu \mathrm{g} \cdot \mathrm{kg}^{-1} \cdot \mathrm{h}^{-1}\right)$, midazolam $\left(0.2 \mathrm{mg} \cdot \mathrm{kg}^{-1} \cdot \mathrm{h}^{-1}\right)$, and pancuronium $\left(0.2 \mathrm{mg} \cdot \mathrm{kg}^{-1} \cdot \mathrm{h}^{-1}\right)$ throughout the entire experiment. Temperature probes were placed into the esophagus and rectum. Optodes for near-infrared spectroscopy (NIRS) were placed over the frontal lobes, with an interoptode distance of $4.0 \mathrm{~cm}$. The receiving optode incorporates 3 detectors. The piglets were in the supine position, and all surgical procedures were performed under sterile conditions. For pressure monitoring, blood sampling, and drug infusion, a catheter (19-gauge Intracath; Becton Dickinson, Sandy, Utah) was inserted into the abdominal aorta through the left superficial femoral artery, and another catheter was introduced through the right femoral vein into the inferior vena cava. After systemic heparinization $(300 \mathrm{IU} / \mathrm{kg}$ ), the chest was entered through a right anterolateral thoracotomy in the third intercostal space, an $8 \mathrm{~F}$ arterial cannula (Bio-Medicus; Medtronic, Inc, Eden Prairie, Minn) was inserted into the abdominal aorta through the right femoral artery, and a $28 \mathrm{~F}$ cannula (Harvey; Bard, Tewksbury, Mass) was inserted for venous drainage through the right atrial appendage.

\section{Experimental Protocol}

The study protocol is depicted in Figure 1. Details of the survival piglet model have been described elsewhere. ${ }^{18-20}$ The 54 piglets were each randomly assigned to one of 12 settings ( 3 bypass conditions and 4 aprotinin dosings), with 4 piglets for each setting. Animals were weaned from the ventilator and extubated early the next morning. Neurologic evaluation was performed every day postoperatively. Animals were killed on postoperative day 4 for histologic assessment.

\section{Experimental Groups}

Brain damage according to bypass conditions. Brain damage according to the bypass protocols has been defined in this model as in our previous studies, namely $10 \mathrm{~mL} \cdot \mathrm{kg}^{-1} \cdot \mathrm{min}^{-1}$ at $25^{\circ} \mathrm{C}$ for mild injury, $10 \mathrm{~mL}$ $\cdot \mathrm{kg}^{-1} \cdot \mathrm{min}^{-1}$ at $34^{\circ} \mathrm{C}$ for moderate injury, or circulatory arrest at $25^{\circ} \mathrm{C}$ for severe injury. The duration of the ultra-low-flow (ULF) bypass or hypothermic circulatory arrest (HCA) period was 60 minutes in each setting.

Aprotinin dosing schedules. No aprotinin (Trasylol; Bayer, West Haven, Conn) was administered in the control group (group C). Aprotinin, $30,000 \mathrm{KIU} / \mathrm{kg}$, was added to the pump prime in the low-dose group (group L). An intravenous bolus infusion of aprotinin of $30,000 \mathrm{KIU} / \mathrm{kg}$ was administered as the loading dose, as well as in the pump prime, followed by maintenance infusion of aprotinin of $10,000 \mathrm{KIU} \cdot \mathrm{kg}^{-1} \cdot \mathrm{h}^{-1}$ in the standard full-dose group (group SF). This dosing regimen was doubled in the double full-dose group (group DF). For all dosing regimens, aprotinin was stopped during HCA and at 5 minutes after weaning from CPB.

\section{CPB Technique}

The CPB circuit consisted of a roller pump, membrane oxygenator (Minimax; Medtronic, Inc, Anaheim, Calif), and sterile tubing with a 40$\mu \mathrm{m}$ arterial filter. Fresh whole blood from a donor pig was transfused into the prime to adjust the hematocrit level to $30 \%$. Methylprednisolone (30 $\mathrm{mg} / \mathrm{kg}$ ), furosemide $(0.25 \mathrm{mg} / \mathrm{kg})$, sodium bicarbonate $7.4 \%$ (10 mL), cephazolin sodium $(25 \mathrm{mg} / \mathrm{kg})$, fentanyl $(50 \mu \mathrm{g} / \mathrm{kg})$, and pancuronium $(0.5 \mathrm{mg} /$ $\mathrm{kg}$ ) were added to the prime. The $\mathrm{pH}$-stat strategy was used (sweep gas $95 \%$ $\mathrm{O}_{2} / 5 \% \mathrm{CO}_{2}$ ). The gas flow was fixed at $3 \mathrm{~L} / \mathrm{min}$ to obtain an arterial $\mathrm{PCO}_{2}$ of 40 to $45 \mathrm{~mm} \mathrm{Hg}$ (corrected to esophageal temperature). After baseline recordings, $\mathrm{CPB}$ with a flow rate of $100 \mathrm{~mL} \cdot \mathrm{kg}^{-1} \cdot \mathrm{min}^{-1}$ was started, and the animals were perfused for 10 minutes at normothermia (esophageal temperature, $37^{\circ} \mathrm{C}$ ). Ventilation was stopped after the establishment of CPB. The piglets underwent 40 minutes of cooling on CPB to an esophageal temperature of $25^{\circ} \mathrm{C}$ or $34^{\circ} \mathrm{C}$. After cooling, HCA or ULF perfusion at a flow rate of $10 \mathrm{~mL} \cdot \mathrm{kg}^{-1} \cdot \mathrm{min}^{-1}$ was initiated for 60 minutes. Before rewarming, sodium bicarbonate $7.4 \%(10 \mathrm{~mL})$, methylprednisolone $(30 \mathrm{mg} / \mathrm{kg})$, furosemide $(0.25 \mathrm{mg} / \mathrm{kg})$, and mannitol $(0.5 \mathrm{~g} / \mathrm{kg})$ were administered into the pump. During 40 minutes of rewarming, animals were warmed to $37^{\circ} \mathrm{C}$ with a flow rate of $100 \mathrm{~mL} \cdot \mathrm{kg}^{-1} \cdot \mathrm{min}^{-1}$. The heart was defibrillated, if 
necessary. Ventilation (100\% oxygen) was started 10 minutes before weaning from CPB. Also, dopamine was administered by means of continuous drip infusion, if necessary. Protamine $(5 \mathrm{mg} / \mathrm{kg})$ was administered intravenously after the animal was hemodynamically stable. The wounds were closed in a sterile fashion.

\section{Postoperative Management}

Animals remained sedated and paralyzed with a continuous infusion of fentanyl $\left(50 \mu \mathrm{g} \cdot \mathrm{kg}^{-1} \cdot \mathrm{h}^{-1}\right)$, midazolam $\left(0.2 \mathrm{mg} \cdot \mathrm{kg}^{-1} \cdot \mathrm{h}^{-1}\right)$, and pancuronium $\left(0.2 \mathrm{mg} \cdot \mathrm{kg}^{-1} \cdot \mathrm{h}^{-1}\right)$ and were mechanically ventilated with a gradually decreasing oxygen fraction. They were monitored continuously for 12 hours after CPB. The chest tubes were removed, and the animals were weaned from ventilation and extubated.

On postoperative day 4 , all surviving piglets were sedated by means of intramuscular induction with ketamine $(20 \mathrm{mg} / \mathrm{kg})$ and xylazine $(4 \mathrm{mg} /$ $\mathrm{kg})$ and anesthetized with intravenous fentanyl $(50 \mu \mathrm{g} / \mathrm{kg})$. After a midline sternotomy, heparin $(300 \mathrm{IU} / \mathrm{kg})$ was administered, and a cannula was inserted into the bovine trunk. One liter of Plasmalyte solution (Baxter, Deerfield, Ill) was infused through the bovine trunk. Blood was suctioned from the superior vena cava until the perfusate was clear of blood. Then $3 \mathrm{~L}$ of $10 \%$ formalin solution was perfused through the brain in the same manner to accomplish perfusion fixation. The entire head of the piglet was immersed in $10 \%$ formalin for a week, and the brain was harvested and fixed with $10 \%$ formalin solution for histologic assessment. ${ }^{11,18-20}$

\section{Data Collection}

Arterial pressure was monitored continuously throughout each experiment and was recorded every 10 minutes.

Blood gas analyses. Blood gases, including hematocrit values, were measured at baseline; the end of normothermic bypass; 20 and 40 minutes during cooling; every 15 minutes during low flow; 5, 15, 30 and 40 minutes after beginning rewarming; and after the procedure, as needed, with a blood gas analyzer (Bayer 860, Bayer Healthcare).

NIRS. A pair of fiberoptic optodes was attached to the head of the animal with a probe holder after induction of anesthesia. The spacing of optodes was $4.0 \mathrm{~cm}$ in the coronal plane. These 2 optodes, a transmitter, and a receiver of laser light of near-infrared wavelength, were connected to the NIRS device (NIRO-300; Hamamatsu Photonics KK, Hamamatsu City, Japan). This device calculated the tissue oxygenation index (TOI) from the relative concentration changes in oxyhemoglobin and deoxyhemoglobin concentrations and with calculation of the optical path length. ${ }^{19,21}$ Data were recorded every 10 seconds after the induction of anesthesia and for 3 hours after weaning from CPB. Average TOI, which correlates with minimum TOI and TOI at 15 minutes after the onset of ULF or HCA, was calculated. ${ }^{20}$

Renal function. Serum creatinine and blood urea nitrogen (BUN) levels were assessed at baseline and on postoperative day 1 .

Aprotinin concentration. Aprotinin concentrations were measured at baseline, the end of cooling, the end of rewarming, and 3 hours and 12 hours after bypass by using the Uni-test (Unicorn Diagnostics Ltd, London, United Kingdom). ${ }^{22}$ The blood samples were immediately centrifuged, and the plasma was frozen and stored at $-80^{\circ} \mathrm{C}$ until measurement.

Neurologic and behavioral evaluations. After the operation, neurologic and behavioral evaluations were performed at 24-hour intervals beginning on postoperative day 1 , as described previously. ${ }^{18-21}$ The neurologic deficit score (NDS; $500=$ brain death, $0=$ normal) and overall performance category ( 5 = brain death, $1=$ normal) were determined by an animal care technician under the supervision of the senior veterinarian blinded to the experimental protocol.

Histologic assessment. The preparation of the cerebral specimens and the details of histologic analyses have been described previously. ${ }^{18-21}$ Twenty-four areas, including the neocortex, hippocampus, dentate gyrus, caudate nucleus, thalamus, and cerebellum, were examined. Histologic damage was scored by using the following criteria: 5 , cavitated lesions with

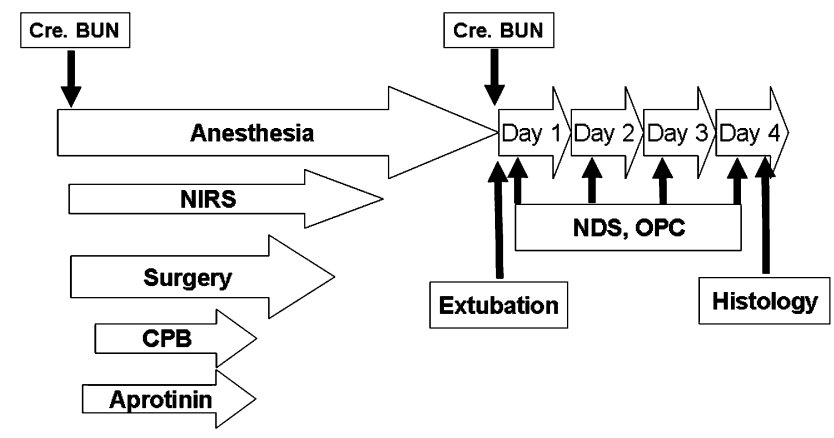

FIGURE 1. Experimental protocol. Cre, Creatinine; $B U N$, blood urea nitrogen; NIRS, near-infrared spectroscopy; $N D S$, neurologic deficit score; $O P C$, overall performance category; $C P B$, cardiopulmonary bypass.

necrosis; 4 , significant damage to neurons; 3 , large clusters of injured neurons; 2, small clusters of damaged neurons; 1 , isolated neuronal damage; and 0 , normal. Scores were summed to determine the total HS (range, 0 120). A single neuropathologist examined all specimens in a blinded fashion.

\section{Statistical Analysis}

Physiologic variables were compared among the 3 bypass conditions before and after CPB by using 1-way analysis of variance (ANOVA) with a 2-tailed $\alpha$-level to protect against committing type I errors (ie, false-positive results). ${ }^{23}$ Mean changes in aprotinin levels and TOI ( $\%$ TOI) were evaluated across different time points by using repeated-measures ANOVA with Greenhouse-Geisser F tests to assess the effects of dose and bypass condition. ${ }^{24}$ NDSs and total HSs were analyzed by using 2-way ANOVA with the Bonferroni adjustment to determine whether these scores were related to differences in aprotinin dose and bypass condition. The linear relationship between NDS and aprotinin concentration was measured for the 33 piglets in the ULF bypass groups by using a Pearson correlation and linear regression model to derive a prediction equation of the form $y=\beta 0+\beta 1 x$, where $\beta 0$ denotes the intercept and $\beta 1$ represents the slope coefficient for the aprotinin concentration at the end of cooling. ${ }^{25}$ Renal function was evaluated at baseline and postoperative day 1 , whereby changes in creatinine and BUN levels were assessed with paired $t$ tests and differences in the $\Delta$ BUN between aprotinin dose groups was compared by means of repeated-measures ANOVA. Linear regression analysis was applied to determine whether body weight was associated with the $\Delta \mathrm{BUN}$ and whether this relationship was dependent on aprotinin dose and bypass condition. Statistical analysis was performed with the SPSS software package (version 16.0; SPSS, Inc, Chicago, Ill). Power analysis was conducted a priori and indicated that a minimum of 12 animals was needed in each aprotinin dose and the control group and randomized equally to the bypass conditions $(n=4)$ to achieve $80 \%$ power for detecting significant dose-response effects with respect to $\%$ TOI, NDS, and total HS based on ANOVA (version 7.0; nQuery Advisor, Statistical Solutions, Saugus, Mass).

\section{RESULTS}

Forty-eight of the 54 animals survived the entire protocol and were killed on postoperative day 4 for histologic assessment. Four piglets subjected to $10 \mathrm{~mL} \cdot \mathrm{kg}^{-1} \cdot \mathrm{min}^{-1}$ at $34^{\circ} \mathrm{C}$ receiving a low dose of aprotinin $(n=2)$, a double full dose of aprotinin $(\mathrm{n}=2)$, or both died after weaning from CPB with sudden ventricular fibrillation. Data from these animals were excluded for analysis. Two piglets subjected to HCA at $25^{\circ} \mathrm{C}$ or ULF at $34^{\circ} \mathrm{C}$ receiving no aprotinin died on postoperative day 1 with sudden death. Data from these piglets were included for analysis, except histologic analysis. 
TABLE 1. Physiologic variables during and after cardiopulmonary bypass*

\begin{tabular}{|c|c|c|c|}
\hline \multirow[b]{2}{*}{ Variable } & \multicolumn{2}{|c|}{ Ultra-low-flow bypass groups } & \multirow{2}{*}{$\begin{array}{c}\text { HCA group } \\
25^{\circ} \mathrm{C}, \text { circulatory arrest }(n=17)\end{array}$} \\
\hline & $25^{\circ} \mathrm{C}, 10 \mathrm{~mL} \cdot \mathrm{kg}^{-1} \cdot \min ^{-1}(\mathrm{n}=16)$ & $34^{\circ} \mathrm{C}, 10 \mathrm{~mL} \cdot \mathrm{kg}^{-1} \cdot \min ^{-1}(\mathrm{n}=17)$ & \\
\hline \multicolumn{4}{|l|}{ Baseline } \\
\hline Temperature $\left({ }^{\circ} \mathrm{C}\right)$ & $36.1 \pm 1.0$ & $35.9 \pm 0.7$ & $36.1 \pm 0.8$ \\
\hline MAP (mm Hg) & $69.1 \pm 13.9$ & $68.9 \pm 11.5$ & $71.5 \pm 13.0$ \\
\hline $\mathrm{pH}$ & $7.51 \pm 0.05$ & $7.51 \pm 0.05$ & $7.52 \pm 0.03$ \\
\hline $\mathrm{PaO}_{2}(\mathrm{~mm} \mathrm{Hg})$ & $83.1 \pm 6.2$ & $74.5 \pm 15.0$ & $79.7 \pm 9.8$ \\
\hline $\mathrm{PaCO}_{2}(\mathrm{~mm} \mathrm{Hg})$ & $39.1 \pm 4.4$ & $40.4 \pm 4.3$ & $39.6 \pm 2.6$ \\
\hline Hematocrit $(\%)$ & $29.1 \pm 3.3$ & $29.7 \pm 3.0$ & $28.3 \pm 2.2$ \\
\hline $\mathrm{SvO}_{2}(\%)$ & $74.6 \pm 6.2$ & $72.7 \pm 8.3$ & $72.3 \pm 6.2$ \\
\hline \multicolumn{4}{|c|}{$12 \mathrm{~h}$ after $\mathrm{CPB}\left(\mathrm{FIO}_{2}=0.25\right)$} \\
\hline Temperature $\left({ }^{\circ} \mathrm{C}\right)$ & $37.2 \pm 0.5$ & $37.1 \pm 0.8$ & $37.0 \pm 0.4$ \\
\hline MAP (mm Hg) & $90.9 \pm 15.8$ & $91.4 \pm 15.0$ & $89.7 \pm 14.4$ \\
\hline $\mathrm{pH}$ & $7.49 \pm 0.06$ & $7.51 \pm 0.05$ & $7.51 \pm 0.07$ \\
\hline $\mathrm{PaO}_{2}(\mathrm{~mm} \mathrm{Hg})$ & $96.4 \pm 15.2$ & $96.4 \pm 24.4$ & $90.3 \pm 19.5$ \\
\hline $\mathrm{PaCO}_{2}(\mathrm{~mm} \mathrm{Hg})$ & $41.7 \pm 3.5$ & $40.5 \pm 3.7$ & $41.4 \pm 4.8$ \\
\hline Hematocrit $(\%)$ & $30.7 \pm 2.9$ & $30.4 \pm 2.3$ & $30.1 \pm 1.9$ \\
\hline $\mathrm{SvO}_{2}(\%)$ & $74.8 \pm 16.4$ & $74.2 \pm 10.4$ & $80.5 \pm 10.0$ \\
\hline
\end{tabular}

Data are presented as means \pm standard deviation. $H C A$, Hypothermic circulatory arrest; $M A P$, mean arterial pressure; $S_{10} O_{2}$, oxygen saturation of venous blood; $C P B$, cardiopulmonary bypass; $\mathrm{FiO}_{2}$, fraction of inspired oxygen. *No significant differences were observed for any variable. Groups were also compared at the end of cooling, rewarming for 5 minutes, the end of bypass, and 6 hours after cardiopulmonary bypass, and no differences were found (2-tailed $P<.01,1$-wat analysis of variance, as the criterion for statistical significance to protect against type I errors caused by multiple comparisons).

\section{Physiologic Parameters and Bypass-Related Variables}

There were no significant differences at baseline for body weight, mean blood pressure, body temperature, blood gases, and hematocrit values between bypass conditions. Also, no significant differences were observed for any parameters at the end of cooling, rewarming for 5 minutes, the end of bypass, and 6 hours after CPB (2-tailed $P<$ .01, 1-way ANOVA, as the criterion for statistical significance to protect against type I errors caused by multiple comparisons; Table 1).

\section{Aprotinin Concentration}

As anticipated, group DF had significantly higher aprotinin concentrations than the other groups $(P<.01)$. Also, group $\mathrm{SF}$ had a higher concentration than groups $\mathrm{L}$ and $\mathrm{C}$ $(P<.02)$. Group $\mathrm{L}$ did not reach a significant difference against group C. Aprotinin concentrations reached a peak value at the end of cooling, namely $289.8 \pm 72.1 \mathrm{KIU} / \mathrm{mL}$ in group DF, $150.6 \pm 103.2 \mathrm{KIU} / \mathrm{mL}$ in group SF and $64.5 \pm 61.7 \mathrm{KIU} / \mathrm{mL}$ in group L, and decreased gradually in all dosing schedules (Figure 2).

\section{Tissue Oxygenation Index}

TOI increased during cooling, decreased rapidly from the onset of ULF or HCA, and reached a nadir in all animals. During $\mathrm{HCA}$ at $25^{\circ} \mathrm{C}$, aprotinin did not influence TOI, even in group DF. However, during $\mathrm{ULF}$ at $25^{\circ} \mathrm{C}$ or $34^{\circ} \mathrm{C}$, the average TOI was $51.9 \% \pm 4.4 \%, 49.1 \% \pm 4.1 \%, 48.6 \% \pm 3.7 \%$, and $46.1 \% \pm 4.9 \%$ in groups $\mathrm{DF}, \mathrm{SF}$, and $\mathrm{L}$ and the control group, respectively. Values in group DF were significantly higher than those in the control group $(P<.05$, Figure 3$)$.

\section{Neurologic and Behavioral Evaluations}

NDSs and overall performance categories showed relatively rapid recovery in all surviving animals. Aprotinin

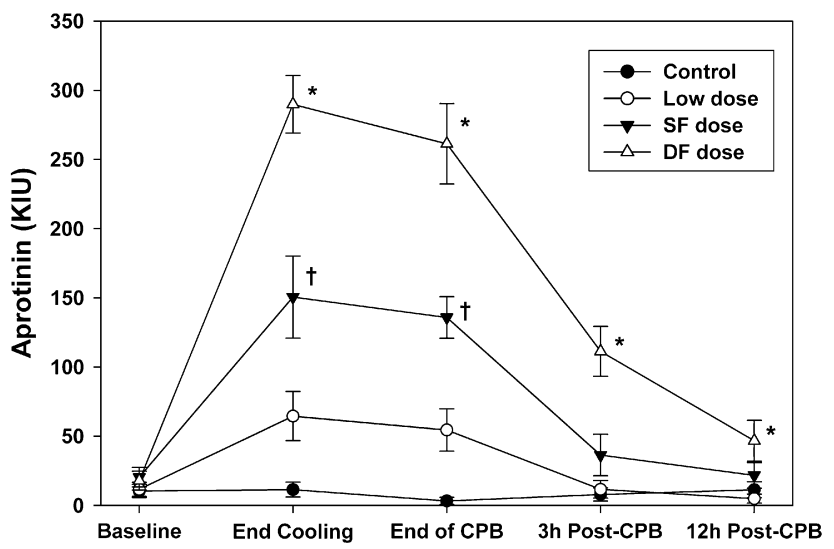

FIGURE 2. The aprotinin concentration was significantly higher $(*)$ in the double full-dose group compared with concentrations seen in the standard full-dose, low-dose, and control groups at the end of cooling, end of bypass, 3 hours after cardiopulmonary bypass $(C P B$; all $\mathrm{P}<.001)$, and 12 hours after cardiopulmonary bypass (all $P<.05$ ). Concentrations were significantly higher in the standard full-dose group $(\dagger)$ than in the low-dose and control groups at the end of cooling and the end of bypass (all $P<.01$ ). Concentrations in the low-dose group were not significantly different from those in the control group at any time point (all $P>.25$ ). Analysis was determined by using repeated-measures analysis of variance with Bonferroni-adjusted group comparisons. $S F$, Standard full dose; $D F$, double full dose. 


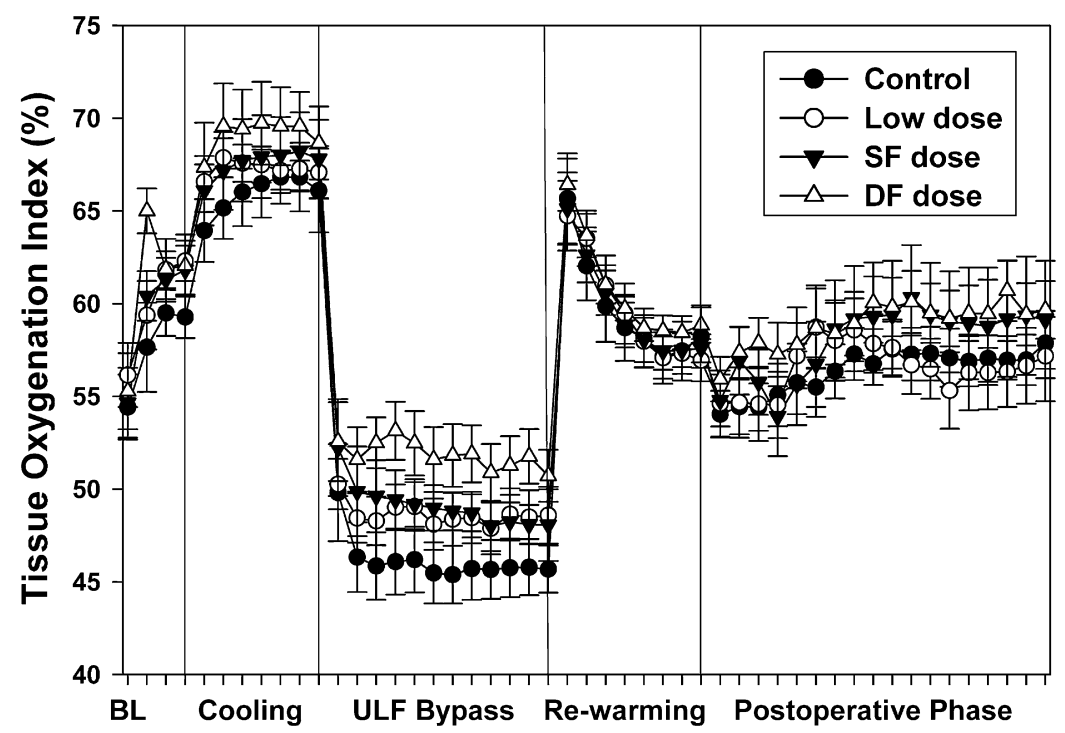

FIGURE 3. The average tissue oxygenation index during ultra-low-flow $(U L F)$ bypass at $25^{\circ} \mathrm{C}$ or $34^{\circ} \mathrm{C}$ in the double full-dose $(D F)$ group was significantly higher than that seen in the control group $(P<.05$, analysis of variance with group comparisons by using the Tukey method). Aprotinin improved oxygenation during ultra-low-flow bypass independent of bypass temperature. Error bars denote standard errors. $S F$, Standard full dose; $B L$, baseline.

was associated with significantly improved neurologic scores on postoperative day 1 after ULF at $25^{\circ} \mathrm{C}$ or $34^{\circ} \mathrm{C}$ $(P<.05)$ but not after HCA $(P=.57$, Figure 4$)$. Linear regression indicated a strong dose-response relationship, with higher aprotinin doses having the best neurologic scores after ULF, where doses are as follows: 0 , none; 1 , low dose; 2 , standard full dose; and 3, double full dose $(r=-0.73, P<$
.01 , Figure 5). Also, a higher aprotinin concentration at the end of cooling was correlated to lower NDSs $(r=-0.57$, $P<.01$, Figure 6).

\section{Histologic Assessment}

Histologic damage was found predominantly in the neocortex, hippocampus, and caudate nucleus. Three animals

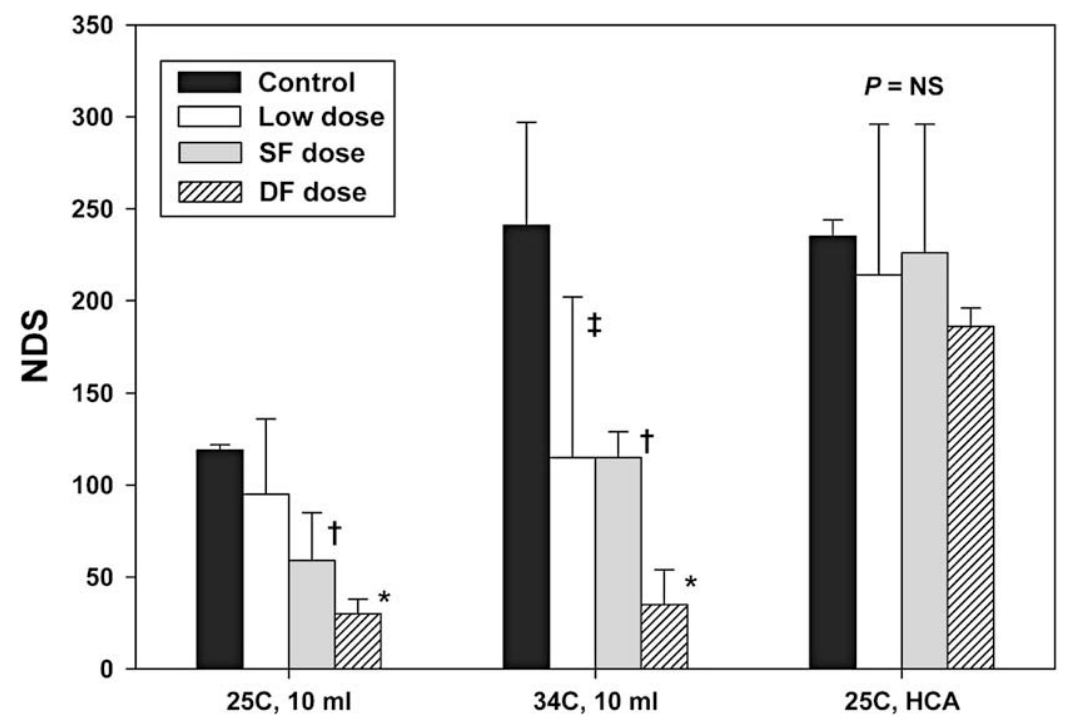

FIGURE 4. Neurologic deficit scores (NDS) on postoperative day 1 according to aprotinin dose for the 3 bypass conditions. Neurologic deficit scores were significantly lower (ie, improved) with aprotinin after ultra-low-flow bypass at $25^{\circ} \mathrm{C}$ or $34^{\circ} \mathrm{C}$ but not after hypothermic circulatory arrest $(\mathrm{P}=.57)$. After ultra-low-flow bypass at $25^{\circ} \mathrm{C}$, neurologic deficit scores were significantly lower in the double full-dose ( $D F$ ) group compared with those in the control group $\left({ }^{*} P<.001\right)$ and the single full-dose $(S F)$ group $(P=.02)$. Neurologic deficit scores were significantly lower in the single full-dose group than in the control group $(\dagger P=.03)$. After ultra-low-flow bypass at $34^{\circ} \mathrm{C}$, neurologic deficit scores were significantly lower in the aprotinin double full-dose group compared with those in the control group $(P<.001)$ and in the single full-dose $(\dagger)$ and low-dose $(\ddagger)$ groups compared with the control group (both $P=.02)$. Analysis was performed by using 2-way analysis of variance with the Bonferroni adjustment for multiple comparisons. Error bars denote standard deviations. NS, Not significant. 


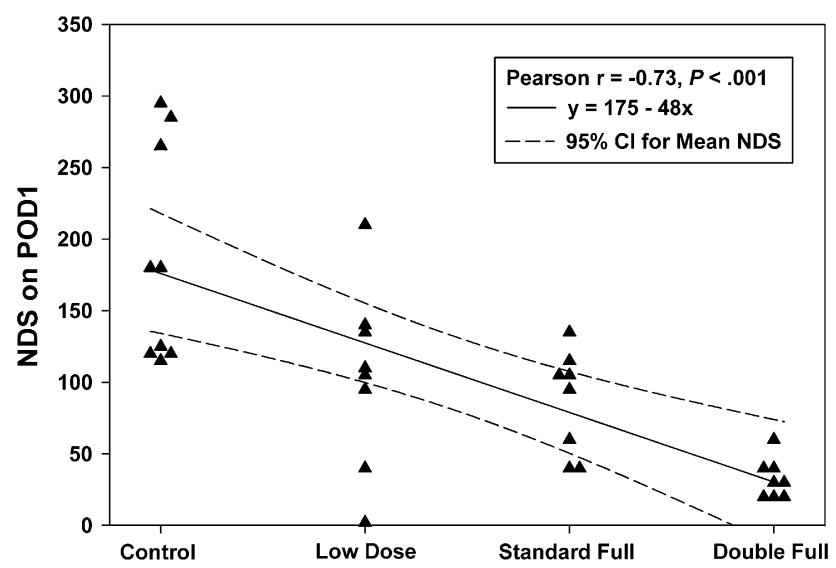

FIGURE 5. Linear relationship between aprotinin dose and neurologic scores for the combined group of 33 piglets undergoing ultra-low-flow bypass $\left(\mathrm{n}=16\right.$ at $25^{\circ} \mathrm{C}$ and $\mathrm{n}=17$ at $\left.34^{\circ} \mathrm{C}\right)$. Linear regression analysis indicated a strong dose-response relationship, with higher aprotinin doses resulting in significantly lower neurologic scores (Pearson $r=-0.73, P<$ $.001)$. The linear equation specifies the aprotinin dosing schedule as follows: none, 0 ; low dose, 1 ; standard full dose, 2; and double full dose, 3 . The model fit was judged to be very good judging from the coefficient of determination (adjusted $R^{2}=0.51$ ), indicating that more than $50 \%$ of the variability in neurologic scores can be accounted for by aprotinin dosing. The $95 \%$ confidence interval for the mean neurologic deficit score (NDS) shows 3 piglets in the control group (no aprotinin) with very high scores. No linear relationship was observed in the hypothermic circulatory arrest group $(P=$ $.22, \mathrm{n}=17)$. POD1, Postoperative day 1 .

assigned to ULF at $25^{\circ} \mathrm{C}$ with no aprotinin or a standard full dose or ULF at $34^{\circ} \mathrm{C}$ with a standard full dose of aprotinin had no brain damage. In control animals, as anticipated, there were significant differences in total HSs between bypass conditions $(P<.01)$ as follows: mild injury (ULF at $25^{\circ} \mathrm{C}$ ), $0.8 \pm 0.5$; moderate injury ( $\mathrm{ULF}$ at $34^{\circ} \mathrm{C}$ ), $9.8 \pm$ 7.2; and severe injury ( $\mathrm{HCA}$ at $25^{\circ} \mathrm{C}$ ), $14.8 \pm 4.2$ (Figure 7). Aprotinin did not influence histologic outcomes in any bypass conditions, although scores after the condition of $\mathrm{ULF}$ at $25^{\circ} \mathrm{C}$ were significantly lower than those after $\mathrm{ULF}$ at $34^{\circ} \mathrm{C}$ or $\mathrm{HCA}$ at $25^{\circ} \mathrm{C}$ (Figure 7).

\section{Renal Function}

Overall creatinine and BUN values significantly increased at postoperative day 1 , from $0.8 \pm 0.3$ to $1.3 \pm 0.8 \mathrm{mg} / \mathrm{dL}$ and from $8.9 \pm 3.8$ to $30.1 \pm 10.9 \mathrm{mg} / \mathrm{dL}$, respectively. Multivariate analysis showed that bypass conditions and aprotinin dosing schedules had no influence on renal function (Figure 8). Also, the peak aprotinin concentration did not correlate with renal outcomes. Lower body weight was the only predictor of a higher BUN value on postoperative 1 $(r=-0.39, P<.01$, Figure 9$)$.

\section{DISCUSSION}

This study demonstrates that aprotinin improves functional neurologic recovery in animals with mild or moderate

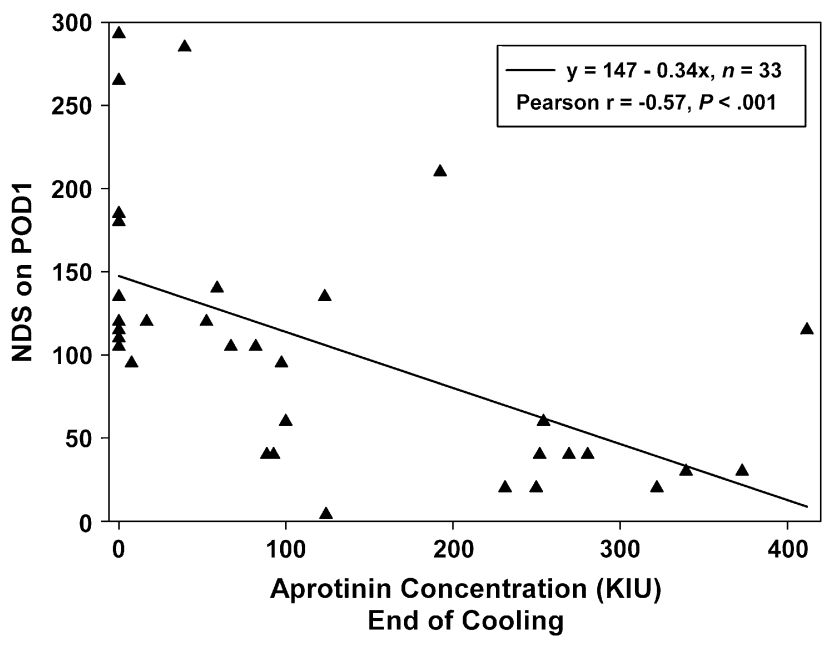

FIGURE 6. Linear regression analysis depicts a moderately strong inverse relationship between the aprotinin concentration at the end of cooling and neurologic deficit score (NDS) on postoperative day 1 (POD1; Pearson $r=-0.57, P<.001)$. The regression line predicts a lower neurologic deficit score with higher aprotinin concentrations (solid line). Analysis is based on piglets undergoing ultra-low-flow bypass $(\mathrm{n}=33)$ because the hypothermic circulatory arrest group did not show a relationship between aprotinin concentration and neurologic deficit score. Multiple regression revealed that although neurologic deficit scores tend to be higher for $34^{\circ} \mathrm{C}$ and $10 \mathrm{~mL}$ than for $25^{\circ} \mathrm{C}$ and $10 \mathrm{~mL}$, the significance of aprotinin concentration as a predictor of neurologic deficit score stands for both conditions.

brain injury after ULF CPB. The beneficial effects of aprotinin are dose dependent over the dosage regimens applied in this study. The beneficial effect of aprotinin was not seen in animals with severe brain injury after circulatory

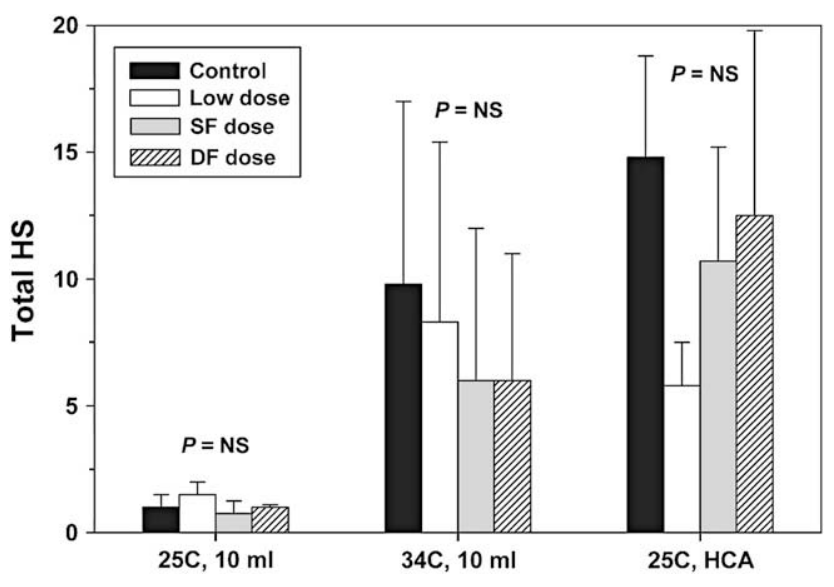

FIGURE 7. Total histologic scores according to aprotinin dose for the 3 bypass conditions. Analysis of variance with Bonferroni comparisons revealed no significant differences in total histologic scores $(H S)$ among the 4 groups (control and aprotinin doses) for any of the bypass conditions $\left(25^{\circ} \mathrm{C}\right.$ and $10 \mathrm{~mL}, P=.12 ; 34^{\circ} \mathrm{C}$ and $10 \mathrm{~mL}, P=.82$; hypothermic circulatory arrest $[H C A], P=.10)$. Error bars denote standard deviations. $S F$, Single full-dose; $D F$, double full-dose; $N S$, not significant. 

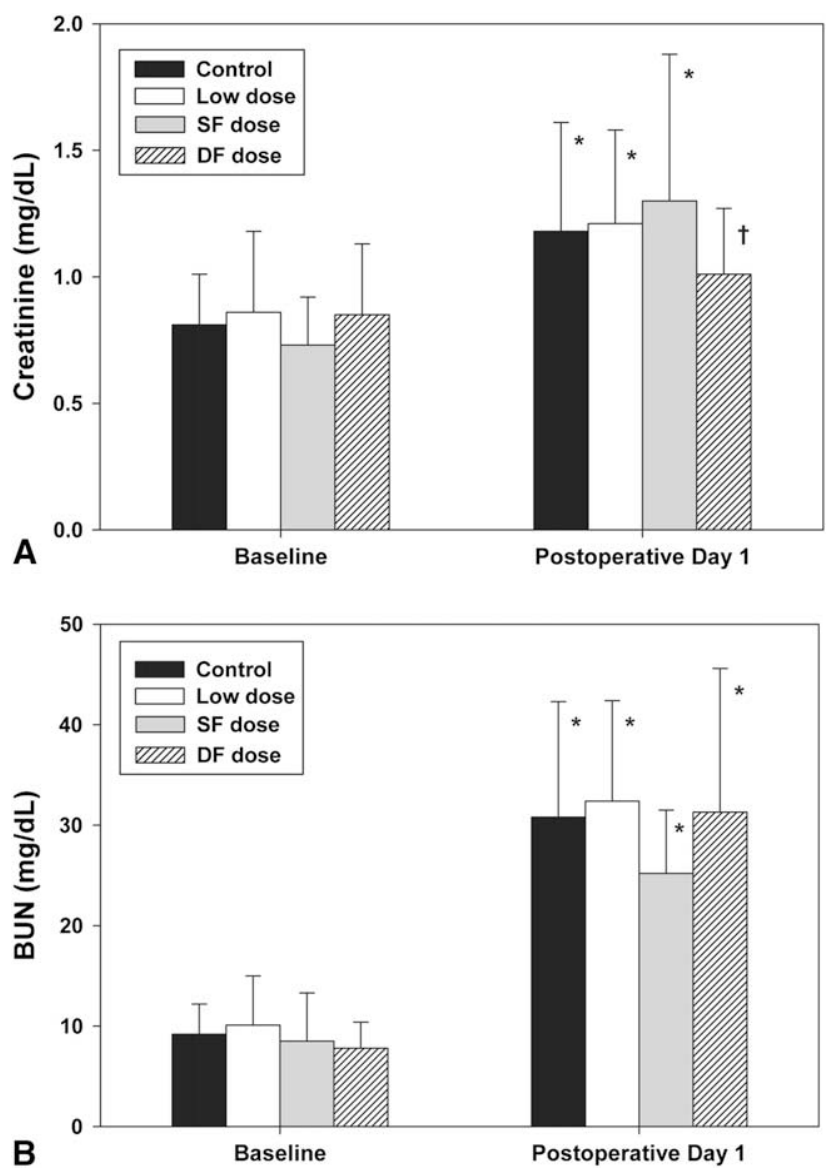

FIGURE 8. Renal function evaluated by changes in creatinine and blood urea nitrogen $(B U N)$ values. Creatinine values $(\mathrm{A})$ increased on postoperative day $1(* P<.01$ and $\dagger P<.05$, paired $t$ tests), although the amount of change did not differ with respect to aprotinin dose $(P=.08$, analysis of variance). Blood urea nitrogen (B) values increased significantly in all groups by approximately 3 -fold (all $P<.01$ ). Error bars denote standard deviations. Additional statistical analysis with repeated-measures analysis of variance indicated that changes in creatinine values were not significantly related to aprotinin dose $(P=.79)$ or specific bypass conditions $(P=$ $.18)$ and changes in blood urea nitrogen values were not dependent on aprotinin dose $(P=.36)$ or bypass conditions $(P=.13)$. $S F$, Single full-dose; $D F$, double full-dose.

arrest. This result suggests that aprotinin might have influenced blood flow under ULF states and is consistent with our previous studies, which suggest that vascular preservation is an important mechanism of action of aprotinin. On the other hand, Anttila and coworkers ${ }^{11}$ reported that aprotinin improved NDSs, even after DHCA at $15^{\circ} \mathrm{C}$. This difference might be explained by the severity of brain injury, which was moderate in the study by Anttila and coworkers, whereas it was severe in our study.

In our study aprotinin did not improve HSs in any bypass condition, including those in which there was an improvement in NDSs. Anttila and coworkers ${ }^{11}$ also reported that aprotinin did not improve HSs after DHCA. We have re-

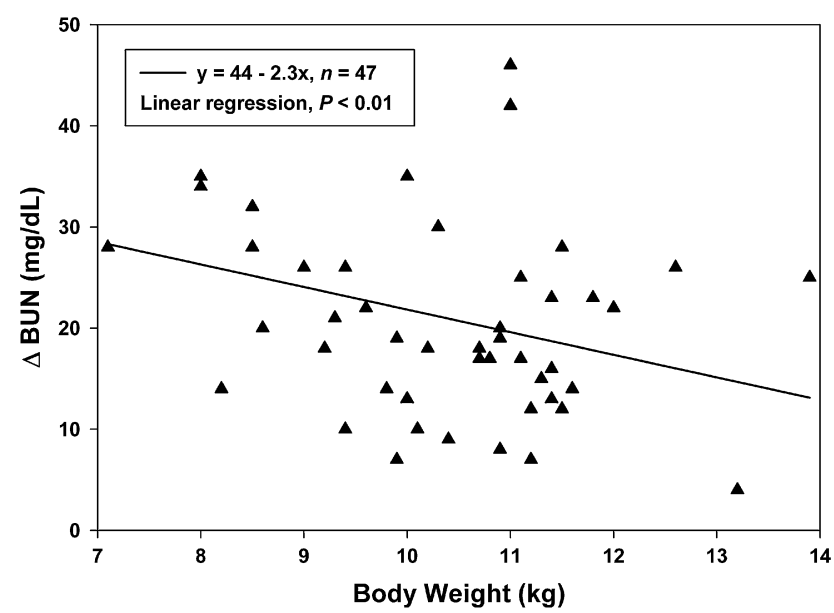

FIGURE 9. Inverse relationship between body weight and change in blood urea nitrogen $(B U N)$ value $(r=-0.39, \mathrm{n}=47)$. Linear regression analysis indicates that lower body weight was predictive of a greater increase in blood urea nitrogen values at postoperative day $1(P<.01)$ and that this relationship is independent of aprotinin dose and bypass conditions. For example, a piglet weighing $9 \mathrm{~kg}$ is expected, on average, to have an increase in blood urea nitrogen value of $24 \mathrm{mg} / \mathrm{dL}$, whereas a 13-kg piglet is expected to have an increase of $14 \mathrm{mg} / \mathrm{dL}$. The solid line represents the fitted regression line, where $x$ is body weight in kilograms.

ported previously that NDSs at postoperative day 1 correlate with total HSs. ${ }^{26}$ In this study NDSs at postoperative day 1 after ULF did not correlate with total HSs. This discrepancy might result from our histologic evaluation method, which focused on necrotic neuronal cell death. Kurth and asssociates $^{27}$ reported that apoptosis plays a key role in neuronal cell death after DHCA. It is known that aprotinin reduces apoptosis. For example, Eser and colleagues ${ }^{28}$ reported that aprotinin decreased apoptotic cell death after brain ischemia. We also have confirmed that aprotinin reduces apoptotic cell death caused by serum deprivation at the concentration of $100 \mathrm{KIU} / \mathrm{mL}$ using a cell culture model (data not shown). Thus reduction of apoptotic neuronal cell death by aprotinin might contribute to improved neurologic outcome.

\section{Renal Function}

Aprotinin did not influence renal function with any dosing regimen in this study, although creatinine and BUN values increased at postoperative day 1 in all conditions. Lower body weight, but not aprotinin use, was predictive of higher BUN values at postoperative day 1 by means of multivariate analysis.

Aprotinin has a high affinity for renal tissue and is rapidly eliminated from the circulation, necessitating a continuous infusion after a bolus dose to maintain a targeted concentration of aprotinin. ${ }^{29}$ The proximal tubular cells absorb and metabolize aprotinin. Feindt and coworkers ${ }^{7}$ demonstrated in adults that renal dysfunction could result from tubular damage caused by aprotinin, which increases 
$\alpha_{2}$-microglobulin and total protein values in urine, although they did not find relevant changes in serum creatinine levels. They concluded that patients with normal renal function preoperatively were able to compensate for both the perioperative renal dysfunction caused by CPB and the additional tubular workload imposed by aprotinin. Our data confirm that animals with normal renal function are able to compensate for the stress of surgical intervention, CPB, and aprotinin, even at a double full-dose regimen. This finding is consistent with clinical reports that have looked at renal function in children with aprotinin use. Although there has been a trend toward higher creatinine levels postoperatively with aprotinin use, this has not been clinically significant. ${ }^{30}$

\section{Aprotinin Concentration}

In this study aprotinin concentration reached a peak at the end of cooling and was $150 \mathrm{KIU} / \mathrm{mL}$ in group SF and 280 $\mathrm{KIU} / \mathrm{mL}$ in group $\mathrm{DF}$, as determined by means of functional assay. ${ }^{22}$ Aprotinin inhibits plasmin at a concentration of 50 $\mathrm{KIU} / \mathrm{mL}$ (hemostatic effect) and kallikrein (anti-inflammatory) at a concentration of $200 \mathrm{KIU} / \mathrm{mL}$ in vitro. In vivo it is thought that a large molar excess of aprotinin up to 125 and 250 to $500 \mathrm{KIU} / \mathrm{mL}$, respectively, is required to inhibit plasmin and kallikrein. ${ }^{31}$ The original high-dose Hammersmith hospital regimen aimed to achieve at least $200 \mathrm{KIU} /$ $\mathrm{mL}$, as determined by means of immunologic assay. ${ }^{32,33}$ The results of our current study support the notion that a dose as high as double the current standard pediatric dose might be more effective in improving functional outcome while not impairing renal function.

\section{Brain Oxygenation}

We have reported previously that TOI is a useful monitor of brain oxygenation during CPB and that average TOI correlates with brain damage. ${ }^{19-21,26}$ In the present study double full-dose aprotinin significantly increased TOI during ULF but did not influence the decrease in TOI during HCA. This result is consistent with our previous finding that aprotinin improves cerebrovascular protection.

\section{Direct Neuronal Protection and the Role of the Blood-Brain Barrier}

Although our previous cell-culture studies have demonstrated that aprotinin, like other serine protease inhibitors, can reduce excitotoxic brain injury, the present study does not shed light as to how important that mechanism might be in improving functional outcome, as observed in this study. Improved vascular protection of the brain and generalized anti-inflammatory effects alone might explain the fact that animals recovered more rapidly on the first day after surgical intervention when aprotinin was used. Furthermore, the ability of aprotinin to cross the blood-brain barrier so as to be able to have a direct neuronal effect is not assessed in the present study.

\section{CONCLUSION}

Our data suggest that aprotinin improves neurologic recovery without compromising renal function in the piglet. Well-designed aprotinin dose-response studies are needed to assess the safety versus efficacy of aprotinin in the clinical setting, particularly a double full-dose strategy. Pediatric surgeons will continue to explore pharmacologic strategies to reduce the hemorrhagic and inflammatory consequences of $\mathrm{CPB}$, which undoubtedly delay recovery from congenital cardiac procedures, especially in the very young.

We thank Inger Hogan for technical support and animal care. We also thank Laura Young for preparation of the manuscript.

\section{References}

1. Westaby S. Aprotinin in perspective. Ann Thorac Surg. 1993;55:1033-41.

2. Levy JH, Pifarre R, Schaff HV, Horrow JC, Albus R, Spiess B, et al. A multicenter, double-blind, placebo-controlled trial of aprotinin for reducing blood loss and the requirement for donor-blood transfusion in patients undergoing repeat coronary artery bypass grafting. Circulation. 1995;92:2236-44.

3. Kawasuji M, Ueyama K, Sakakibara N, Tedoriya T, Matsunaga Y, Misaki T, et al. Effect of low-dose aprotinin on coagulation and fibrinolysis in cardiopulmonary bypass. Ann Thorac Surg. 1993;55:1205-9.

4. Nuttall GA, Fass DN, Oyen LJ, Oliver WC Jr, Ereth MH. A study of a weight-adjusted aprotinin dosing schedule during cardiac surgery. Anesth Analg. 2002;94: 283-9.

5. Cosgrove DM 3rd, Heric B, Lytle BW, Taylor PC, Novoa R, Golding LA, et al. Aprotinin therapy for reoperative myocardial revascularization: a placebo-controlled study. Ann Thorac Surg. 1992;54:1031-6.

6. Sundt TM 3rd, Kouchoukos NT, Saffitz JE, Murphy SF, Wareing TH, Stahl DJ. Renal dysfunction and intravascular coagulation with aprotinin and hypothermic circulatory arrest. Ann Thorac Surg. 1993;55:1418-24.

7. Feindt PR, Walcher S, Volkmer I, Keller HE, Straub U, Huwer H, et al. Effects of high-dose aprotinin on renal function in aortocoronary bypass grafting. Ann Thorac Surg. 1995;60:1076-80.

8. Mangano DT, Tudor IC, Dietzel C. Multicenter Study of Perioperative Ischemia Research Group, Ischemia Research and Education Foundation. The risk associated with aprotinin in cardiac surgery. $N$ Engl J Med. 2006;354:353-65.

9. Kamiya T, Katayama Y, Kashiwagi F, Terashi A. The role of bradykinin in mediating ischemic brain edema in rats. Stroke. 1993;24:571-6.

10. Aoki M, Jonas RA, Nomura F, Stromski ME, Tsuji MK, Hickey PR, et al. Effects of aprotinin on acute recovery of cerebral metabolism in piglets after hypothermic circulatory arrest. Ann Thorac Surg. 1994;58:146-53.

11. Anttila V, Hagino I, Iwata Y, Mettler BA, Lidov HG, Zurakowski D, et al. Aprotinin improves cerebral protection: evidence from a survival porcine model. $J$ Thorac Cardiovasc Surg. 2006;132:948-53.

12. Buisson A, Nicole O, Docagne F, Sartelet H, Mackenzie ET, Vivien D. Up-regulation of a serine protease inhibitor in astrocytes mediates the neuroprotective activity of transforming growth factor beta1. FASEB J. 1998;12:1683-91.

13. Vivien D, Buisson A. Serine protease inhibitors: novel therapeutic targets for stroke? J Cereb Blood Flow Metab. 2000;20:755-64.

14. Yepes M, Sandkvist M, Wong MK, Coleman TA, Smith E, Cohan SL, et al. Neuroserpin reduces cerebral infarct volume and protects neurons from ischemia-induced apoptosis. Blood. 2000;96:569-76.

15. Nicole O, Docagne F, Ali C, Margaill I, Carmeliet P, MacKenzie ET, et al. The proteolytic activity of tissue-plasminogen activator enhances NMDA receptormediated signaling. Nat Med. 2001;7:59-64.

16. Lebeurrier N, Liot G, Lopez-Atalaya JP, Orset C, Fernandez-Monreal M, Sonderegger $\mathrm{P}$, et al. The brain-specific tissue-type plasminogen activator inhibitor, neuroserpin, protects neurons against excitotoxicity both in vitro and in vivo. Mol Cell Neurosci. 2005;30:552-8.

17. Iwata Y, Nicole O, Okamura T, Zurakowski D, Jonas RA. Aprotinin confers neuroprotection by reducing excitotoxic cell death. J Thorac Cardiovasc Surg. 2008; 135:573-8.

18. Forbess JM, Ibla JC, Lidov HG, Cioffi MA, Hiramatsu T, Laussen P, et al. University of Wisconsin cerebroplegia in a piglet survival model of circulatory arrest. Ann Thorac Surg. 1995;60(suppl):S494-500. 
19. Sakamoto T, Hatsuoka S, Stock UA, Duebener LF, Lidov HG, Holmes GL, et al. Prediction of safe duration of hypothermic circulatory arrest by near-infrared spectroscopy. J Thorac Cardiovasc Surg. 2001;122:339-50.

20. Hagino I, Anttila V, Zurakowski D, Duebener LF, Lidov HG, Jonas RA. Tissue oxygenation index is a useful monitor of histologic and neurologic outcome after cardiopulmonary bypass in piglets. J Thorac Cardiovasc Surg. 2005;130:384-92.

21. Shin'oka T, Shum-Tim D, Jonas RA, Lidov HG, Laussen PC, Miura T, et al. Higher hematocrit improves cerebral outcome after deep hypothermic circulatory arrest. J Thorac Cardiovasc Surg. 1996;112:1610-21.

22. Cardigan RA, Mackie IJ, Gippner-Steppert C, Jochum M, Royston D, Gallimore MJ. Determination of plasma aprotinin levels by functional and immunologic assays. Blood Coagul Fibrinolysis. 2001;12:37-42.

23. Cabral HJ. Multiple comparison procedures. Circulation. 2008;117:698-701.

24. Wallenstein S, Zucker CL, Fleiss JL. Some statistical methods useful in circulation research. Circ Res. 1980;47:1-9.

25. Harrell FE Jr. Regression modeling strategies. With applications to linear models, logistic regression, and survival analysis. New York: Springer; 2001. p. 11-40.

26. Sakamoto T, Zurakowski D, Duebener LF, Lidov HG, Holmes GL, Hurley RJ, et al. Interaction of temperature with hematocrit level and $\mathrm{pH}$ determines safe duration of hypothermic circulatory arrest. J Thorac Cardiovasc Surg. 2004;128:220-32.

27. Kurth CD, Priestley M, Golden J, McCann J, Raghupathi R. Regional patterns of neuronal death after deep hypothermic circulatory arrest in newborn pigs. $J$ Thorac Cardiovasc Surg. 1999;118:1068-77.

28. Eser O, Kalkan E, Cosar M, Buyukbas S, Avunduk MC, Aslan A, et al. The effect of aprotinin on brain ischemic-reperfusion injury after hemorrhagic shock in rats: an experimental study. J Trauma. 2007;63:373-8.

29. Rustom R, Grime JS, Maltby P, Stockdale HR, Critchley M, Bone JM. Observations on the early renal uptake and later tubular metabolism of radiolabelled aprotinin (Trasylol) in man: theoretical and practical considerations. Clin Sci (Lond). 1993;84:231-5.

30. Backer CL, Kelle AM, Stewart RD, Suresh SC, Ali FN, Cohn RA, et al. Aprotinin is safe in pediatric patients undergoing cardiac surgery. $J$ Thorac Cardiovasc Surg. 2007; 134:1421-6.

31. Fritz H, Wunderer G. Biochemistry and applications of aprotinin, the kallikrein inhibitor from bovine organs. Arzneimittelforschung. 1983;33:479-94.

32. Royston D, Bidstrup BP, Taylor KM, Sapsford RN. Effect of aprotinin on need for blood transfusion after repeat open-heart surgery. Lancet. 1987;2:1289-91.

33. Bidstrup BP, Royston D, Sapsford RN, Taylor KM. Reduction in blood loss and blood use after cardiopulmonary bypass with high dose aprotinin (Trasylol). J Thorac Cardiovasc Surg. 1989;97:364-72.

\section{Discussion}

Dr Aubyn Marath (Portland, Ore). I want to thank the Association for the privilege of discussing this article. Dr Ungerleider regrets he cannot be here.

Dr Iwata, I was very pleased and impressed with your coping with the language problems and also the very nice presentation of your article. I have 4 questions, 2 of which were Dr Ungerleider's. I am going to read them to you.

You demonstrate a mild postsurgical increase in BUN and creatinine values in your models of altered flow that is consistent regardless of the dose of aprotinin and is similar when no aprotinin is given. Do you have any data from the neonatal animals that you examined that are exposed to less disturbing strategies of perfusion to see whether there is any difference in renal function when the aprotinin is administered? Also, do you have any normal bypass control animals, with and without aprotinin, with respect to renal function?

Dr Iwata. Aprotinin has a high affinity for the renal tissues and is eliminated from the circulation by glomerular filtration, with resorption by the proximal tubules. Thus a continuous infusion is required.

We have demonstrated that both creatinine and BUN values increase after surgical intervention on postoperative day 1 under the stressful conditions of our experiment. The increases were not influenced by any specific bypass condition or by the aprotinin dosing schedules. However, we do not have data yet regarding the effect of less stressful bypass conditions with and without aprotinin. We are presently conducting such studies.

Dr Marath. What are your thoughts about why aprotinin is protective at mild and moderate levels of neuroinjury? You know, mild neuroinjury we can accept, but what about severe injury? Specifically, do you think this relates to an anti-inflammatory mechanism that is going on?

Dr Iwata. Aprotinin has 3 different neuroprotective effects. As I presented last year at this meeting, aprotinin directly protects neurons against ischemic insult based on our work with neuronal cell cultures. Aprotinin also reduces inflammation. We have also demonstrated previously that aprotinin protects against mild cerebrovascular insult by improving the cerebral microcirculation with reduced neutrophil activation.

Dr Marath. In your article, and I think you alluded to it in one slide, I liked the comment you made in your introduction when you stated correctly that the adjustment of body weight and blood level has generally not been monitored. I think this is an important point in your observations.

One of the questions I wanted to ask was this. I was very impressed with your histologic mapping of the target areas of the brain. Recognizing that you have to put the pig's head in formalin for a week or so, have you done any cerebrovascular assessment of the piglets? Because in human subjects, as you know, there is quite marked variation in cerebrovascular anatomy, up to $35 \%$, for instance, in the circle of Willis variations in anatomy.

Dr Iwata. No, we have not specifically studied the cerebrovascular anatomy of the piglet. We believe the ischemic insult of circulatory arrest is a global insult and is not influenced by the individual piglet anatomy. 